\title{
Impact of Diabetes Mellitus Type 1 on Lebanese Families' Quality of Life
}

\author{
${ }^{1}$ Balsam Noueiri, ${ }^{2}$ Nahla Nassif
}

\begin{abstract}
Introduction: Diabetes mellitus type 1 (DM1) markedly alters the lives of individuals and their families. Family members can be affected by diabetes and its treatment, causing burden, distress, and reduced quality of life (QOL).
\end{abstract}

Objective: The aim of this research is to study the relationship between the diabetic child and the family members, to evaluate the stress and emotional issues between siblings, and to weigh in on the psychological, affective, and financial burden that parents have to deal with in their daily life.

Materials and methods: A total of 37 diabetic Lebanese families recruited from the Chronic Care Center (CCC) answered two questionnaires, one about general information and the other related to psychological and financial impact of DM1 and its oral complications on the families.

Results: About $56.8 \%$ have monthly income below $\$ 1,000$; $16.2 \%$ of parents have an educational upper limit of college degree; $83.8 \%$ of the mothers are housewives; $75.7 \%$ of parents feel guilty about their child's condition; $89.2 \%$ feel that their diabetic child is frustrated with their diet. For $78.4 \%$, the siblings are jealous of the diabetic child; $13.5 \%$ of parents are well aware of the oral complications of diabetes and $86.5 \%$ think that treating the diabetic child's teeth is more important than the siblings' ones; $91.9 \%$ assist their diabetic child's toothbrushing, but $81.1 \%$ of family members do not visit the dentist regularly. A total of $100 \%$ allocate special budget for the diabetic child's diet and $59.4 \%$ have an additional budget dedicated to the diabetic child's treatment; $81.1 \%$ declared that their career is affected by their child's illness.

Conclusion: The diabetic child expressed frustration with their diet. The child's siblings are jealous as they feel left behind. The parents experienced guilt feeling and psychological stress. They have social restriction and financial problems. The QOL of families living with a diabetic child is altered negatively.

Keywords: Diabetes mellitus type 1, Diabetic child, Family burden, Guilt feeling.

How to cite this article: Noueiri B, Nassif N. Impact of Diabetes Mellitus Type 1 on Lebanese Families' Quality of Life. Int J Clin Pediatr Dent 2018;11(2):61-65.

\footnotetext{
${ }^{1,2}$ Associate Professor

1,2Department of Pediatric Dentistry, Lebanese University Beirut, Lebanon
}

Corresponding Author: Balsam Noueiri, Associate Professor Department of Pediatric Dentistry, Lebanese University, Beirut Lebanon, Phone: +009613388328, e-mail: dr.balsam@live.com

\section{Source of support: Nil}

Conflict of interest: None

\section{INTRODUCTION}

People with diabetes live in a society that does not understand their condition. To make the situation worse, only few people understand that diabetes is a condition that cannot be simply controlled by medication and that the presence of diabetes markedly alters the lives of individuals and their families. ${ }^{1}$

Williams et $\mathrm{al}^{2}$ reported that little is known about the individual and family factors associated with diabetesspecific family conflict. They examined whether background factors, diabetes variables, and psychological distress in parents and children and adolescents were associated with diabetes-specific family conflict. Furthermore, they studied the linkage between parental distress and family-level distress as it has not been examined fully in children and adolescents with diabetes. Their findings suggested a close link between psychological distress in parents and children and adolescents and reports of increased diabetes-specific family conflict.

Although family influence is perceived both positively and negatively, most people with diabetes welcome their support as it plays a crucial role in maintaining lifestyle changes and optimizing diabetes management. But diabetes and its treatment still affect the life of family members in several ways, causing, for example, different types of psychological distress. Family members can be adversely affected by diabetes and its treatment, causing burden, distress, and reduced QOL. ${ }^{3-6}$

As Burns et $\mathrm{al}^{7}$ found the relationship between QOL in individuals with diabetes and family members unclear, they conducted, in 2013, the first multinational study surveying adults with diabetes and their adult family members and health care providers. The results showed that diabetes has a substantial negative effect on family members of people with diabetes.

Although there are extensive studies that evaluate the medical, social, and psychological impact of diabetes on children, until now not many discuss the disease and its direct impact on family members, and even fewer investigate the financial issues in relation to diabetes and its oral complications. 
The present research conducted on Lebanese families aims to study the relationship between the diabetic child and the family members, to evaluate the stress and emotional issues between siblings, and to weigh in on the psychological, affective, and financial burden that parents have to deal with in their daily life.

\section{MATERIALS AND METHODS}

A cross-sectional approach was utilized to conduct this study. Our population of interest was 37 Lebanese diabetic children's families from the CCC. The CCC is a Lebanese private nonlucrative institution with a multidisciplinary medical team for preventing and monitoring certain chronic childhood diseases including DM1. With the help of one researcher, the parents answered two questionnaires. The first one consisted of 4 questions about general information related to socioeconomic factors, and the second one (13 questions) related to psychological and financial impact of DM1 and its oral complications on the families.

A consent form with a written approval was signed by the parents for their inclusion in the study.

The answers were scored on a three-point scale: $0=$ never or not at all, $1=$ moderately, and $2=$ excessively.

The answers collected were then statistically analyzed using Statistical Package for the Social Sciences (version 18.0). The chi-square test was used to determine the level of association between variables. The level of significance was set at $\mathrm{p}<0.05$.

\section{RESULTS}

Table 1 shows that $56.8 \%$ have monthly income below 1,000 USD, $40.5 \%$ between 1,000 and 1,500 USD, and 2.7\% have above 1,500 USD; $35.2 \%$ of the fathers and $40.5 \%$ of the mothers have an educational level of primary degree; $48.6 \%$ of fathers, $43.3 \%$ of mothers reach the high school level and $16.2 \%$ of both parents have an educational

Table 1: Financial and educational status of family members

\begin{tabular}{llll}
\hline & & \multicolumn{2}{l}{ Proportions } \\
& Values (USD) & in \% & p-value \\
\hline Family monthly income & $<1,000$ & 56.8 & 0 \\
& $1,000-1,500$ & 40.5 & \\
\multirow{4}{*}{ Father's education } & $>1,500$ & 2.7 & \\
level & Primary & 35.2 & 0.053 \\
& High school & 48.6 & \\
Mother's education & College & 16.2 & \\
level & Primary & 40.5 & 0.085 \\
& High school & 43.3 & \\
Does the mother work & College & 16.2 & \\
outside of the house? & Yes & 83.8 & 0 \\
\hline
\end{tabular}

upper limit of college degree; $83.8 \%$ of the mothers are housewives.

In Table 2, for $35.1 \%$ of parents, there is no difference between raising a diabetic child and their other children. However, $75.7 \%$ of parents feel guilty about their child's condition and $97.3 \%$ of mothers need to stay by the side of the diabetic child more than the norm; $89.2 \%$ of parents feel that their diabetic child is frustrated when his siblings eat sweets and adversely $78.4 \%$ of parents testified that the siblings are jealous of the diabetic child.

A total of $13.5 \%$ of parents are well aware of the oral complications of diabetes and $86.5 \%$ think that treating the

Table 2: Impact of DM1 on the family members' behavior

\begin{tabular}{|c|c|c|c|}
\hline & \multicolumn{3}{|c|}{ Proportions } \\
\hline & Values & in $\%$ & $p$-value \\
\hline \multirow{3}{*}{$\begin{array}{l}\text { Is there any difference between } \\
\text { raising a diabetic child and their } \\
\text { nondiabetic siblings? }\end{array}$} & 0 & 35.1 & \multirow[t]{3}{*}{0.704} \\
\hline & 1 & 37.8 & \\
\hline & 2 & 27.1 & \\
\hline \multirow{3}{*}{$\begin{array}{l}\text { Do you feel guilty about the } \\
\text { diabetic child's condition? }\end{array}$} & 0 & 24.3 & \multirow[t]{3}{*}{0.368} \\
\hline & 1 & 32.5 & \\
\hline & 2 & 43.2 & \\
\hline \multirow{3}{*}{$\begin{array}{l}\text { Does the mother feel the need } \\
\text { to be by her diabetic child's side } \\
\text { more than the norm? }\end{array}$} & 0 & 2.7 & \multirow[t]{3}{*}{0} \\
\hline & 1 & 21.6 & \\
\hline & 2 & 75.7 & \\
\hline \multirow{3}{*}{$\begin{array}{l}\text { Do the siblings of the diabetic } \\
\text { child feel any sort of jealousy } \\
\text { toward him/her? }\end{array}$} & 0 & 21.6 & \multirow[t]{3}{*}{0.027} \\
\hline & 1 & 24.3 & \\
\hline & 2 & 54.1 & \\
\hline \multirow{3}{*}{$\begin{array}{l}\text { Do you feel your diabetic child } \\
\text { frustrated when their siblings are } \\
\text { eating sweets? }\end{array}$} & 0 & 2.7 & \multirow[t]{3}{*}{0} \\
\hline & 1 & 8.1 & \\
\hline & 2 & 89.2 & \\
\hline \multirow{3}{*}{$\begin{array}{l}\text { Are you aware of the oral } \\
\text { complications of diabetes? }\end{array}$} & 0 & 54.1 & \multirow[t]{3}{*}{0.01} \\
\hline & 1 & 32.4 & \\
\hline & 2 & 13.5 & \\
\hline \multirow{3}{*}{$\begin{array}{l}\text { Do you think that treating your } \\
\text { diabetic child's teeth is more } \\
\text { important than treating his/her } \\
\text { sibling's teeth? }\end{array}$} & 0 & 13.5 & \multirow[t]{3}{*}{0} \\
\hline & 1 & 18.9 & \\
\hline & 2 & 67.6 & \\
\hline \multirow{3}{*}{$\begin{array}{l}\text { Do family members visit the } \\
\text { dentist regularly? }\end{array}$} & 0 & 81.1 & \multirow[t]{3}{*}{0} \\
\hline & 1 & 10.9 & \\
\hline & 2 & 8 & \\
\hline \multirow{3}{*}{$\begin{array}{l}\text { Does the mother assist her } \\
\text { diabetic child's teethbrushing } \\
\text { more than that of her other } \\
\text { children? }\end{array}$} & 0 & 8.1 & \multirow[t]{3}{*}{0} \\
\hline & 1 & 21.6 & \\
\hline & 2 & 70.3 & \\
\hline \multirow{3}{*}{$\begin{array}{l}\text { Do you allocate a special budget } \\
\text { for the diabetic child's oral } \\
\text { health? }\end{array}$} & 0 & 35.1 & \multirow[t]{3}{*}{0.469} \\
\hline & 1 & 40.5 & \\
\hline & 2 & 24.4 & \\
\hline \multirow{3}{*}{$\begin{array}{l}\text { Is there an additional budget } \\
\text { allocated to the diabetic child's } \\
\text { treatment? }\end{array}$} & 0 & 40.6 & \multirow[t]{3}{*}{0.012} \\
\hline & 1 & 48.6 & \\
\hline & 2 & 10.8 & \\
\hline \multirow{3}{*}{$\begin{array}{l}\text { Do you allocate a special budget } \\
\text { for the diabetic child's diet? }\end{array}$} & 0 & 0 & \multirow[t]{3}{*}{0} \\
\hline & 1 & 16.2 & \\
\hline & 2 & 83.8 & \\
\hline \multirow{3}{*}{$\begin{array}{l}\text { Does the diabetic child's } \\
\text { condition affect your career? }\end{array}$} & 0 & 18.9 & 0.085 \\
\hline & 1 & 48.6 & \\
\hline & 2 & 32.5 & \\
\hline
\end{tabular}


diabetic child teeth is more important than the siblings' ones. Moreover, $91.9 \%$ of parents assist their diabetic child's teethbrushing but $81.1 \%$ of families' members do not visit the dentist regularly.

A total of $100 \%$ of parents allocate special budget for the diabetic child's diet and 59.4\% have an additional budget dedicated to the diabetic child's treatment. The career of only $18.9 \%$ of parents is not affected by their child's illness.

\section{DISCUSSION}

The present study shows that few families have a monthly income over 1500 USD, the majority of both fathers and mothers interrupt their education before reaching college, and most of the mothers are housewives (Table 1). The latter reflects the modest socioeconomic level of our sample, which flows logically by their belonging to the nonlucrative institution, the CCC.

The treatment of DM1 is multifactorial, implicating the active participation of the whole family. ${ }^{8}$ In the same spirit, Correia Junior et $\mathrm{al}^{9}$ declared that DM interferes not only in the child but also in the family and social group, imposing profound modification in the lifestyle. Moreover, Williams et $\mathrm{al}^{2}$ declared that pediatric type 1 diabetes is often characterized as a "family disease" because of the important role of family interactions and parental support.

Almost two-thirds of parents admitted that they treat their diabetic child differently from their other children, and $97.3 \%$ of mothers feel the need to stay by their diabetic child's side more than the norm (Table 2). It can be due to the fact that parents need to keep their child under supervision in order to control the glycemia in fear of its complications. According to Martins et $\mathrm{al}^{10}{ }^{10}$ the diabetic child's mother fears the possibility of the occurrence of hypoglycemia when she is not around. Bennadi and Reddy, ${ }^{11}$ in their study about oral health-related QOL, mentioned that research on QOL has gained interest and visibility in recent decades, internationally. "How" we live and not just "how long" we live has increasingly become recognized as a central issue in health care and health research. They concluded that the perception of QOL has a subjective component and therefore, varies from one culture to another. The fact that the majority of mothers are housewives (Table 1) indicates that the care of their diabetic children falls back on them and requires their continuous presence around. Indeed, it is verified that DM interferes not only in the child but also in the family and social group, imposing profound modification in the lifestyle, and the main care is under the mother's responsibility. ${ }^{9}$

Three-quarters of parents feel responsible of their child's condition. This guilt feeling is common in all ethnicities and cultures. Cavini et $\mathrm{l}^{12}$ explained this feeling by the fact that mothers take responsibility for household care, so when the child falls ill, they blame themselves and feel despair which leads them to offset these feelings in the most intense care for children. Bowes et $\mathrm{al}^{13}$ mentioned that continuous feelings associated with grief, such as anger and guilt, were expressed by both fathers and mothers. In the same spirit, de Brito and Sadala ${ }^{8}$ reported that the parents punish themselves for the treatment and restriction imposed by the disease and end up following a protectionist policy regarding the child, which make them totally dependent.

The parents' guilt feeling and special attention toward their diabetic child could create jealousy between siblings as indicated in the obtained results (Table 2). In fact, 78.4\% of parents admitted that their healthy children feel jealous of their diabetic sibling. Manshaee et $\mathrm{al}^{14}$ declared that siblings can express jealousy toward their diabetic brother or sister. It might be explained by their young age, their possessive feeling toward their mothers, and their limited ability to cope with stress.

Although the solidarity between the family members is an essential part of the treatment of DM1 implicating the active participation of the whole family, not only the diabetic child, ${ }^{8,15}$ Correia Junior et $\mathrm{al}^{9}$ highlighted that the attention turned to the family's diabetic member makes the other children of the couple feel left aside, and many times, they feel jealousy and injustice.

Vice versa, the diabetic child can express frustration and anger when they are deprived from sweets while their siblings are having some (Table 2). Considering the young age of the diabetic children in our sample (6-12 years old), it is understandable that they are not able to deal with their restricted diet; $97.3 \%$ of parents reported that their diabetic children can express nonsatisfaction and anger. It can be interpreted by the fact that the diabetic child surrounded and supported continuously by the family cannot stand a situation of deprivation. Walker et $\mathrm{al}^{16}$ reported that food-related issues are universally identified as a source of frustration and it is openly acknowledged as a source of diabetes-specific conflict within homes.

Concerning the oral complications and their multifactorial impacts on families, Alves et $\mathrm{al}^{17}$ stated that there is no doubt that patients need to be thoroughly informed about the risks of oral complications associated with the disease. In the present study, only $13.5 \%$ of parents are totally aware, $32.4 \%$ are partially aware, and $54.1 \%$ ignore the relation between DM1 and its oral complications. This poor awareness might be related to the parents' low level of education as shown in Table 1 . Valerio et $\mathrm{al}^{18}$ reported that lack of awareness and understanding of the 
relationship between diabetes and oral health may be an indicator of inadequate oral health literacy. A study in Portugal showed a significant relationship between low education of parents and poor glycemic control. Highly educated parents can be more oriented to the symptoms and complications of DM1 compared with less educated parents and it can be effective for better control of the disease. ${ }^{19}$ Another study in Kingdom of Saudi Arabia indicated that mothers with higher education had diabetic children with better glycemic control. ${ }^{20}$

A total of $86.5 \%$ of parents admit that they have tendency to prioritize the treatment of their diabetic child's teeth more than that of their other children. It could be explained mostly by their guilt feeling (43.2\%) and financial condition $(56.8 \%<1000$ USD) as shown in Table 1.

Only $13.5 \%$ of parents consider that treating their nondiabetic children's teeth is just as important as treating their diabetic child's teeth and $81.1 \%$ of family members are not regular in their dental visits $(p=0.000)$. Those results could be explained by the fact that few parents are aware of general oral complications of DM1 (13.5\%), the relatively high cost, the low income, and the fact that dental treatments are not covered by the social security in Lebanon.

A total of $91.9 \%$ of parents are present during their diabetic child's teethbrushing. It might be explained by the parent's guilt feeling and the continuous presence of the mother's need to stay by the side of her diabetic child. Parents of children with DM1 perceive less cohesion and feel more anxiety and stress about parenting tasks compared with parents of healthy children. ${ }^{21}$ When DM is present in childhood, researches show the mother as the primary caregiver and her guidance is necessary once she takes care of her child. ${ }^{10}$ Correia Junior et al ${ }^{9}$ emphasized the importance of the mothers' presence next to their diabetic child: they alter their activities for the welfare of the sick child, favoring the treatment and the assistance of the chronic disease once the transformation occasioned by the diagnosis of DM is inevitable.

The results on a special budget allocated to oral health were not statistically significant $(p=0.469)$.

On the contrary, parents reported that they assign special budgets for the treatment of diabetes $(p=0.012)$ and the required diet $(p=0.000)$. Even though the CCC provides their patients with insulin and blood glucose monitoring units, $10.8 \%$ of parents reported a struggle to cover the expenses of their child's treatment and $83.8 \%$ for the special diet. It can be due to the low financial income of the majority of the families as shown in Table 1. Correa Junior et $\mathrm{al}^{9}$ highlighted the financial cost as a determinant factor for the family members to adhere to the treatment of a diabetic child, once the long-term treatment makes financial dynamic onerous, due to the acquisitions of flasks of insulin, glucometer, and its strips and the syringes to apply medication and expenditures with food.

About $81 \%$ of parents find that their child's condition affects their career due to absence. They reported that it is essentially due to mandatory regular medical visits to the CCC and sometimes due to the sickness of their child. Mandic et $\mathrm{al}^{22}$ mentioned that caring for children with medical complexity frequently impacts employment and careers of caregivers and spouses. Employed and nonemployed caregivers invest substantial time in care.

Moreover, Martins et $\mathrm{al}^{10}$ considered mothers as the main person responsible for their children, as they abdicate their own appointments in order to assume the therapeutic procedures and glycemic control, living in function of the sickness of the child.

\section{CONCLUSION}

The main findings of this study show that the diabetic child was properly supervised and his life was well framed inside the family. Despite the special attention, the diabetic child expressed frustration regarding their restricted diet. Diabetic child's family members perceived many functional problems in their daily life. Parents experienced guilt feeling and psychological stress due to their child's condition. Moreover, they expressed a social restriction and financial problems to cope with. The findings also pointed toward emotional issues perceived by the diabetic child's siblings as they feel left behind. All these relevant results indicate that the QOL of families living with a diabetic child is altered negatively. In order to improve their wellbeing, it is very important to provide them more help by offering special psychological support to manage the difficulties of diabetes. Furthermore, low-income Lebanese families must receive financial aid from the Lebanese government or local nongovernmental organizations dedicated to improve the oral health of all members.

\section{REFERENCES}

1. Debono M, Cachia E. The impact of diabetes on psychological well being and quality of life. The role of patient education. Psychol Health Med 2007 Oct;12(5):545-555.

2. Williams LB, Laffel LM, Hood KK. Diabetes-specific family conflict and psychological distress in pediatric Type 1 diabetes. Diabet Med 2009 Sep;26(9):908-914.

3. Rintala TM, Jaatinen P, Paavilainen E, Astedt-Kurki P. Interrelation between adult persons with diabetes and their family: a systemic revue of literature. J Fam Nurs 2013 Feb;19(1):3-28.

4. Rosland AM, Heisler M, Choi HJ, Silveira MJ, Piette JD. Family influences on self-management among functionally independent adults with diabetes or heart failure: do family members hinder as much as they help? Chronic Illn 2010 Mar;6(1):22-33.

5. Malerbi FE, Nigrato CA, Gomes MB; On behalf of the Brazilian Type 1 Diabetes Study Group. Assessment of psycho social 
variables by parents of youth with type 1 diabetes mellitus. Diabetol Metab Syndr 2012 Nov;4:48.

6. Haugstvedt A, Wentezel-Larsen T, Rokne B, Graue M. Perceived family burden and emotional distress: similarities and differences between mothers and fathers of children with type 1 diabetes in a population-based study. Pediatr Diabetes 2011 Mar;12(2):107-114.

7. Kovacs Burns K, Nicolucci A, Holt RI, Willaing I, Hermanns N, Kalra S, Wens J, Pouwer F, Skovlund SE, Peryot M; DAWN2 Study Group. Diabetes Attitudes, Wishes and Needs second study (DAWN2): cross-national benchmarking indicators for family members living with people with diabetes. Diabet Med 2013 Jul;30(7):778-788.

8. de Brito TB, Sadala ML. Diabetes mellitus juvenil: a experiência de familiares de adolescentes e pré-adolescentes. Ciênc Saúde Coletiva 2009 May-Jun;14(3):947-960.

9. Correia Júnior PC, Pereira SM, Almeida VC, Saraiva AR, Alencar AM. Assimilating the impact of diabetes mellitus in children under the perspective of mothers. Revista da Rede de Enfermagem do Nordeste 2015;15(1):60-69.

10. Martins EM, Ataide MB, Silva DM, Frota MA. Experience of mothers in the care of children with type 1 Diabetes. Rev Rene 2015;14(1):42-49.

11. Bennadi D, Reddy CV. Oral health related quality of life. J Int Soc Prev Community Dent 2013 Jan-Jun;3(1):1-6.

12. Cavini FL, Gonçalves KA, Cordeiro SM, da Silva Moreira D, Resck ZM. Experiences of diabetic adolescents: a phenomenological approach. J Nurs UFPE Line Recife 2016 Feb;10(Suppl2): 805-813.

13. Bowes S, Lowes L, Warner J, Gregory JW. Chronic sorrow in parents of children with type 1 diabetes. J Adv Nurs 2009 May;65(5):992-1000.

14. Manshaee G, Hariri M, Aqarashti Z, Khanbani F. Assessment of family functioning in patients with psychosomatic disorders (diabetes, hypertension, heart disease). J Sociol Res 2014;5(1):171-181.

15. Sales CA, Tironi NM, D'Artibale EF, da Silva MA, Violin MR, Castilho BC. O cuidar de uma Crianca com Diabetes mellitus tipo 1: concecoes dos cuidadores informais. Rev Eletr Enf 2009;11(3):563-572.

16. Walker A, Schatz D, Johnson C, Silverstein J, Lyles S, Rohrs H. Type 1 diabetes through two lenses: comparing adolescent and parental perspectives with photovoice. Int J Pediatr Endocrinol 2016 Jan;2016:2.

17. Alves C, Brandao M, Andion J, Menezs R. Oral health knowledge and habits in children with type 1 diabetes mellitus. Braz Dent J 2009;20(1):70-73.

18. Valerio MA, Kanjirath PP, Klausner CP, Peters MC. A qualitative examination of patient awareness and understanding of type 2 diabetes and oral health care needs. Diabetes Res Clin Pract 2011 Aug;93(2):159-165.

19. Marques Rde M, Fornés NS, Stringhini ML. Socioeconomic, demographic, nutritional, and physical activity factors in the glycemic control of adolescents with type 1 diabetes mellitus. Arq Bras Endocrinol Metabol 2011 Apr;55(3): 194-202.

20. Al-Odayani AN, Alsharqi OZ,Ahmad AM, Khalaf Ahmad AM, Al-Borie HM, Qattan AM. Children's glycemic control: mother's knowledge and socioeconomic status. Glob J Health Sci 2013 Oct;5(6):214-226.

21. Moreira H, Frontini R, Bullinger M, Canavarro MC. Family cohesion and health-related quality of life of children with type 1 diabetes: the mediating role of parental adjustment. J Child Fam Stud 2014;23(2):347-359.

22. Mandic CG, Johaningsmeir S, Coden TE, Earle A, AcevedoGarcia D, Gordo JB. Impact of caring for children with medical complexity on parents' employment and time. Community Work Fam 2016 Jun;20(4):444-458. 